\title{
Corrigendum
}

\section{Corrigendum to "Application of Deep Learning in Neuroradiology: Brain Haemorrhage Classification Using Transfer Learning"}

\author{
Awwal Muhammad Dawud $\left(\mathbb{D}\right.$, Kamil Yurtkan $\left(\mathbb{D}^{\circ}\right.$, and Huseyin Oztoprak \\ Cyprus International University, Faculty of Engineering, Department of Computer Engineering, Nicosia, Northern Cyprus, \\ Mersin 10, Turkey \\ Correspondence should be addressed to Awwal Muhammad Dawud; awwal125@gmail.com \\ Received 27 July 2020; Accepted 27 July 2020; Published 28 August 2020 \\ Copyright (c) 2020 Awwal Muhammad Dawud et al. This is an open access article distributed under the Creative Commons \\ Attribution License, which permits unrestricted use, distribution, and reproduction in any medium, provided the original work is \\ properly cited.
}

In the article titled "Application of Deep Learning in Neuroradiology: Brain Haemorrhage Classification Using Transfer Learning" [1], the faculty name was missing from the affiliation. The corrected authors' list and affiliation are shown above.

\section{References}

[1] A. M. Dawud, K. Yurtkan, and H. Oztoprak, "Application of deep learning in neuroradiology: brain haemorrhage classification using transfer learning," Computational Intelligence and Neuroscience, vol. 2019, Article ID 4629859, 12 pages, 2019. 